\title{
GROUP APPROACHES AND ARMY HEALTH
}

\author{
MAJ J R BIRD, MRCPsych, DPM, RAMC \\ Queen Elizabeth Military Hospital, Woolwich
}

SUMMARY: The use of group approaches in military life is reviewed from a historical perspective, particularly the development of group psychotherapy by British Army psychiatrists in World War II.

The difficulty that the soldier and his wife may have in coping with the stresses of service life, in establishing group and personal identity and in relating to others is highlighted.

The value of group methods as prophylaxis and treatment by social, welfare or medical workers in the community and hospital setting is discussed.

\section{Introduction}

In ancient China, so Craven and Sharp ${ }^{1}$ report, families would employ a physician and only pay him as long as all family members remained healthy. This assured the very best in preventive care and husbanded family resources. Fortunately, for the Army doctor his remuneration is not so precarious.

However, the point should not be lost that a significant contribution can be made by the physician in the maintenance of health and the improvement of the quality of life of his patient population.

At a time of concern with the loss of trained manpower from the services, perhaps greater attention can be paid to the precipitating and underlying factors leading to such loss. These, whether affecting the young recruit, the older soldier or the family, may be amenable to change or resolution at an early stage.

Rycroft $^{2}$ defined a group as, "a number of persons united for some purpose or possessing common interests, aspirations, functions or fears ....". In essence, a group approach, in which a varying number of people meet regularly together with a trained helper, is economical in terms of time and available resources and a highly specific and purposive treatment method.

Military life presents many common difficulties and stresses and is an ideal setting in which to undertake group work. The Army is, after all, a large group formed from many smaller sub-groupings and every group reflects the tensions and difficulties experienced by all members whilst still containing within it individual stress.

A treatment group offers many and varied forms of help:-

(a) It provides a forum for the sharing of problems. (b) It provides a setting for mutual help. (c) It increases a sense of personal and group identity. (d) It can deal with specific or general problems. (e) It can cope with individual crises. (f) It gives its members a place to express feelings that might not otherwise be verbalized but acted out. (g) It offers members an opportunity to scrutinize themselves and personal patterns of behaviour. (h) It will, as a result, in- 
crease personal awareness and can influence selection and choice of response, maturation and personality development.

Treatment in a group is not a panacea for all ills. Nor is group treatment without disadvantage or risk. However, the selective use of group counselling or psychotherapy can undoubtedly offer a valuable and meaningful experience, for both members and leaders.

In the author's opinion it can lower the incidence of psychiatric breakdown, reduce the loss of servicemen through personal, social and welfare problems and provide an economical and effective use of our resources.

That group psychotherapy, which developed in the British Army and flourishes throughout the civilian community and the American armed forces, is so little applied within our own military life, is indeed an irony.

\section{A historical perspective}

In a paper on military psychiatry, Arthur ${ }^{3}$ wrote: "Surely the erratic behaviour of Caligula when he placed himself at the head of his Roman legions in the field cried out for psychiatric intervention, but there was to be no formalized psychiatric assistance for almost another two millenia".

Such assistance may have been slow in coming, but has been widely recognized as Gibbs ${ }^{4}$ observes, to have contributed significantly to the understanding of human behaviour under conditions of unusual or excessive stress.

Undoubtedly, the experiences of World War I had much to do with this development producing recognition of 'shell shock', and the gradual acceptance of neurosis as an illness. The concept of forward psychiatry, treatment as close to the front line as possible with rapid return to duty, emerged in 1917 and remains as valid to-day. The need for better selection procedures and the failure during World War I adequately to screen for psychiatric illness in draftees was acknowledged in the United States by Caldwell ${ }^{5}$, but still, in World War II, as Menninger $^{6}$ wryly recorded, there was a failure to learn the lessons of World War I.

Whilst different approaches to treatment had appeared in the 1920s, it was World War II that provided the real impetus to the appreciation and application of group methods in many aspects of military life. Under the guidance of Rees ${ }^{7}$, whose influence on the development of military psychiatry was immense, specific group approaches emerged. An early example was at War Office Selection Boards, where the 'leaderless group' pioneered by $\mathrm{Bion}^{8}$ proved of considerable value in officer selection.

The later use of group methods in the treatment and rehabilitation of psychoneurotic patients at Northfield Military Hospital, is well described by Foulkes ${ }^{9}$ and others ${ }^{10-12}$. This early development, of what was in effect a therapeutic community for the treatment of soldiers in groups, became known as the Northfield Experiment'. These war time military psychiatrists working at Northfield later spread and established group methods of treatment throughout this country and the United States. Menninger ${ }^{13}$ later paid tribute to the contribution of the 
British experience to the development of group psychotherapy in the United States Army.

It is hard to capture, writing over thirty years later, the revolutionary nature of the group work undertaken in the British Army and its profound effect throughout the field of psychiatric approaches. A contribution indeed!

The experience of enlistment, the need for a new recruit to find a place in the strange world of the military and the value of group approaches in establishing unit identity were stressed by Berlieu ${ }^{14}$ and Cohen ${ }^{15}$. The creation of group cohesion within the British Army was greatly aided by the existence of regiments with territorial affiliations. This has long been acknowledged and envied by our American colleagues and it is regrettable that change has removed many of these easily identifiable units.

At a later time, surveying the Vietnam War and high-lighting the need for group support for replacements joining a unit, Bey ${ }^{16}$ wrote, "the combat unit is undoubtedly one of the most closely knit, vitally interdependent groups in existence".

World War I had already demonstrated the value of treating cases of "battle neurosis' close to the front line whenever possible. The maintenance of the patient's group identity with his own fighting unit by prompt and forward management prevented many soldiers becoming psychiatric casualties.

As Miller ${ }^{17}$ pointed out in 1940 , breakdown in the fighting man is a blow to self-respect, self-esteem and an ego ideal. The severing of group ties with a unit, the loss of group identity and the fear of being isolated, stigmatized and mocked, is a major preoccupation confronting any contemporary psychiatrist treating soldiers in a base hospital.

Flood ${ }^{18}$ assessing United Kingdom psychiatric casualties during the Korean conflict noted that it was more the shame of personality disintegration in the face of danger than fear of death or maiming that emerged from psychotherapy with these patients.

In a necessarily brief survey of the historical development of group approaches in military life, it is not possible to expand on other important work. Ahrenfeldt ${ }^{19}$ has recorded the value of group approaches to the resettlement and rehabilitation of the disabled soldier and returning prisoner of war. The former area has particular application in the light of current experience in Ulster. Yet it is questionable whether this lesson from World War II has been well learnt.

\section{The current scene}

Group approaches were developed at Northfield Military Hospital specifically for the soldier. The current military scene is greatly different. The soldier and his family have become, more often than not, the medical responsibility of the Army doctor. An approximate military population of 180,000 men and 250,000 dependants high-lights the size and nature of this responsibility.

An increasing awareness of the need to understand and deal with the effects of service stresses has developed as a result of various papers and welfare reports. In the author's view these stresses can be traced to:- 
(i) A failure to establish an identity within the group - the soldier in the Army, the wife in the military community. (ii) A failure to achieve a mature and responsible personal identity.

The consequences of these failures are emotional response, behavioural disturbance and a breadth of physical and psychological symptomatology. Emotionally, the patient experiences moods ranging from mild dissatisfaction to absolute despair. Depression, anxiety, unhappiness, loneliness and frustration are frequent complaints.

Not surprisingly, behavioural disturbances follows. The range is great but there is a marked frequency of disciplinary problems, excess drinking, marital discord, suicidal gestures and violence. Consistently noted is the wife's inability to handle separations, an issue covered by several authors ${ }^{20-22}$, or doubts regarding her capacity as a mother and fear that she might harm her children.

Lagrose $^{23}$ took particular no.e of the triangular nature of service life, with the family as the third point of the triangle, all too often viewed as only an extension of the soldier. Since this is commonily the view also of the wife, it is not surprising that maturity, independence and a sense of security may fail to develop. There is frequently an inability to adapt in a different environment and culture, away from family, relatives and friends. The balanced homeostasis necessary for family integrity fails to develop and as Cowell ${ }^{24}$ points out changing life events frequently induce episodes of illness.

There is a clear need to retain in the services, skilled personnel. These older, trained servicemen and women often react badly to sudden stress, job dissatisfaction and failures in relating and in relationships. Their view of themselves distorted, ego ideal disturbed, either blame is projected onto the Army or taken personally. All too often they feel they cannot share their feelings with others. They fear they will not be understood or accepted. The end result is often the same; a decision to leave the forces.

At the same time, a percentage of potentially valuable manpower may be lost early in service because of a failure to cope with anxieties, personality problems and service stresses that are felt to represent total inadequacy of self or system, rather than an experience frequently shared by others undergoing a development and maturational period in their lives.

Tables I and II list the symptom presentation of 100 patients (50 soldiers and 50 wives) seen by the author consecutively in psychiatric out-patients at the British Military Hospital, Hannover during 1974.

It is immediately apparent that a majority of these symptoms are not amenable to drug treatment. Indeed a physical form of treatment was felt to be justified for only 16 wives and 11 soldiers, a total of 27 cases ( 27 per cent).

Undoubtedly, what many of these patients need, if one excluded environmental manipulations or administrative action, is a different form of medicine. Balint ${ }^{25}$ wrote, "the most powerful drug a doctor can prescribe is himself". Clearly what he meant was that an effective remedy of considerable potency was the doctor's ability to listen, hold and respond verbally to a patient's need. 
Table I

Symptom presentation-50 soldiers

\begin{tabular}{lr|lr}
\hline Symptom & Patients & Symptom & Patients \\
\hline Problems with service life & 15 & Aggressive outbursts & 7 \\
Alcohol abuse & 14 & Marital discord & 5 \\
Relationship difficulties & 13 & Anxiety - UK based families & 4 \\
Disciplinary troubles & 12 & Severe mood disturbance & 4 \\
Feelings of inadequacy, sexual anxiety, & & Anxiety - Ulster posting & 2 \\
$\quad$ failures in romance & 12 & & 1 \\
Phobias, hypochondriasis & 8 & Psychosis & \\
\hline
\end{tabular}

Table II

Symptom presentation-50 Wives

\begin{tabular}{lr|lr}
\hline Symptom & Patients & Symptom & Patients \\
\hline Problems with service life & 15 & Social anxieties - severe & 8 \\
Relationship difficulties & 15 & Sexual dissatisfaction & 7 \\
Marital discord & 14 & Phobic states & 5 \\
Anxiety-physical symptoms & 12 & Psychosis & 4 \\
Severe mood disturbance & 12 & Alcohol abuse & 3 \\
Fear of abusing child & 10 & Anxiety - Ulster posting & 3 \\
\hline
\end{tabular}

The question is, whether the drug-'doctor' can be as effective and efficient in a group situation as in a one to one treatment. The answer is surely "yes" since many of the problems and symptoms presented are group triggered and always group disturbing. A group approach is frequently an ideal setting in which to tackle the difficulties of relating and relationships, identity and role.

The particular value of group psychotherapy within a military community is described by $\mathrm{Cook}^{26}$ who high-lights two valuable points:-

(i) That many problems of adjustment to military life relate to failures of group interactions. (ii) That treatment of disturbance within the oommunity may prevent the development of a patient role.

Further it was Parrish ${ }^{27}$ who observed that it was the military in World War II who originated a community psychiatric approach that did not develop in civil life until 10 or more years later.

\section{Group approaches - scope and value}

The great majority of problems present within the community. Patients seek out the family doctor, social or welfare worker. It is worth reflecting that people have an expectation, frequently a fantasy, of what the doctor or social worker does and what he represents. As Steiner ${ }^{28}$ noted, these conceptions are based on past experience, cultural and social attitudes. The transaction between doctor and patient is much influenced from the onset by these unspoken internalized views.

A reasonable hope is that the doctor will 'make me well' and the physician is expected to be directive, authoritative, all-knowing. Previously successful contact with the medical man may lead to his being invested with omnipotence. The converse equally applies: We have all met the patient who is totally dismissive 
of our efforts, cynical and aggressive towards the medical profession for past failures. Similarly, the doctor has his expectations and hopes, that the patient will value his efforts and reward him by getting better.

The importance of these mutual feelings, operative at first meeting, are obvious, since many of the problems, difficulties and symptoms are not, in the simplistic sense, amenable to cure. Thus, any failure to achieve the impossible is highly likely to produce mutual disenchantment and shared resentment.

In a different dimension, other forces are operative in the interaction between doctor and patient. The doctor is expected to be Active, the giver, the doer; the patient to be Passive, submissive, the recipient. The value of treating selected patients in groups is that the whole climate and structure of the helping situation is changed. A member of the group is exposed to his peers. The group has equality, everyone has difficulties, and there is a sharing with others, producing a setting in which giving and taking, personal exposure and exploration of self is encouraged. A group can be very tolerant whilst still able to confront, judge, assess, advise and encourage its members in a way that does not happen in individual treatment. Further, a member is far more likely to accept expressed group feelings. Approval or criticism from a peer has special validity.

The group leader is not treating an individual but treating the group, developing and using the group experience and exchanges to foster a therapeutic climate. A climate in which the individual can feel secure and supported, yet exposed to the scrutiny and assessment of others. The particular way in which a group operates, reflects the group approach, the group task, the group leader.

\section{The group approach}

Table III indicates three group approaches and tabulates certain problems that might be treated by these methods.

Table III

Group approaches

\begin{tabular}{l|l|l}
\hline \multicolumn{1}{c|}{ Counselling } & \multicolumn{1}{|c}{ Psychotherapeutic } & \multicolumn{1}{c}{ Behavioral } \\
\hline Domestic difficulties & Personality disorder & Social skills \\
Service life stresses & Neurotic symptoms & Obesity \\
Separation anxieties & Relationship problems & Smoking \\
Resettlement and & Doubts - identity & Phobias \\
rehabilitation & Doubts - sexuality & Alcoholism \\
Marital discord & Marital discord & \\
Alcoholism & Alcoholism & \\
\hline
\end{tabular}

It will be clear that these lists are not exclusive and overlap occurs. The essential choice as to which group approach is chosen depends both on the group task and the orientation, skill and training of the group leader.

Further, a generic label barely captures the full range of possible problems. For instance, 'domestic difficulties' covers the whole range of family disturbances; failıre to settle as a wife, anxieties regarding maternal role, debt, fear of harming children and so forth. 
'Service life stresses' can include all the disturbance of adjustment that might affect the wife, newly married or not, the older soldier facing retirement, or the young soldier struggling to adjust. This latter area has attracted considerable attention from Moffett and Stoklosa ${ }^{29}$.

\section{The group task}

Any group meeting together has a recognised task. A selection board is expected to produce an acceptable candidate, a planning group, a plan. The task, in a treatment group, may be to support, advise and encourage as occurs in a counselling group where more conscious and clear areas of anxiety and disturbance can be identified. Or change may be sought at a deeper level, particularly in patterns of behaviour, response and adaptation, a task of psychotherapeutic groups. A directive approach aimed at symptom relief, with a focus on specific problems, is a valuable task for a group on behaviour therapy lines.

\section{The group leader}

We live, develop and grow in groups; teaching and training is group orientated. There is, however, undoubted difficulty in stimulating doctors and social workers to undertake treatments in a group setting. This in the author's view reflects primarily a greater sense of personal comfort in the helper working in a one to one setting, increased by the patient's natural wish to receive undivided attention. In addition, group dynamics, group treatments and group methods are not widely taught.

Understandably, there is a resistance or anxiety to the idea of undertaking an approach that exposes us to group scrutiny and group tensions. If further there are doubts, real or imaginary, regarding the efficacy and efficiency of group treatment, then powerful forces exist to prevent change.

This was indeed the climate of doubt confronting the pioneers at Northfield, expressed by administrators, other medical staff and the patients themselves. The concept of a non-directive, therapeutic community functioning in a war time military establishment has a certain chilling quality! The truth is that it worked, and was felt to work by the original doubters.

The running of groups is not the preserve of the psychiatrist. Within the community or hospital setting the potential, indeed need, for group approaches undoubtedly exists. The diverse skills of psychiatrists, general practitioners, social workers, psychologists, community psychiatric and registered mental nurses could be applied in a less narrow fashion, benefiting a wider clientele and increasing. I am certain, the helper's own sense of real accomplishment.

\section{Conclusion}

Just as the statement, "it is a soldier's duty to be fit" emphasises a clear requirement, so also does a directive for the medical services, "to maintain the health of the Army".

A concept of health conveys much more than the sheer absence of illness. There may be disturbances in aspects of personal life which seriously under- 
mine the well being and happiness of the soldier and his family.

Many of the symptoms, problems and stresses brought to medical and welfare attention are not illness and do not respond to drug treatment. Nor can situational or environmental manipulation always be the answer.

The value of treating some of these patients in a group setting has been high-lighted. The group may be essentially counselling or psychotherapeutic, and function within the community or in a hospital. It brings together, not only patients with difficulties shared by others, but medical and welfare workers sharing care.

That the British Army has pioneered group methods of treatment, now applied world wide, is something of which we can be justifiably proud. This heritage we are perhaps in danger of losing through neglect.

\section{REFERENCES}

1. Craven, $R$ and Sharp, B (1972). The effects of illness on family functions. Nurs Forum 11, 2-9.

2. RYCROFT, C C (1968). A Critical Dictionary of Psychoanalysis. Nelson, London.

3. ARTHUR, R J (1978). Reflections on military psychiatry. Am J Psychiatry 135, 2-7.

3. GIBBS, J J (1973). Military psychiatry: Reflections and projections. Psychiatr Opinn 10, 20-23.

5. CALDWELL, J H (1967). In Psychiatry. Ed by A. M. Freeman and H I Caplan. Williams \& Wilkins, Baltimore.

6. MENNINGER, W C (1947). Pyschiatric experience in the war 1941-1946. Am J Psychiatry 103, $577-586$.

7. REES, J R (1945). The Shaping of Psychiatry by War. W W Norton. New York.

8. BION, W R (1946). The leaderless group project. Bull Menninger Clin 10, 77-81.

9. FouLKES, S H (1946). Group analysis in a military neurosis centre. Lancet i, 303-306.

10. BRIDGER, $H$ (1946). The Northfield experiment. Bull Menninger Clin 10, 71-76.

11. Sutherland, J D and FitzPatrick, G A (1945). Some approaches to group problems in the British Army. Sociometry 8, 443-448.

12. FoulKES, S H (1964). Therapeutic Group Analysis. George Allen \& Unwin. London.

13. MenNinger, W C (1948). Psychiatry in a Troubled World. MacMillan. New York.

14. Berleu, I C (1954). Psychiatric aspects of military manpower conservation. Am J Psychiatry 111, 91-99.

15. COHEN, $R$ (1944). Factors in adjustment to Army life. War Medicine 5, 83-91.

16. BEY, D R (1972). Group dynamics and the FNG in Vietnam. Int $J$ Group Psychother 22, 22-30.

17. MiLLeR, E (1940). The Neuroses in War. MacMillan. London.

18. Flood, J J (1954). Psychiatric casualties in UK elements of the Korean Force. $J R$ Army Med Corps 100, 40-47.

19. AHRENFELDT, $R \mathbf{H}$ (1958). Psychiatry in the British Army in the Second World War. Routledge \& Keen, London.

20. Pearlman, C A (1970). Separation reactions of married women. Am J Psychiatry 126, 946-950.

21. BEY, D R and LANGe, J C (1974). Waiting wives: women under stress. Am J Psychiatry 131, 283-286.

22. Gonzalez, V R (1970). Psychiatry and the Army Brat. Charles C Thomas. Illinois.

23. LAGROSE, D M (1978). The military family syndrome. Am J Psychiatry 1040-1043.

24. Cowell, D D C (1978). The family dimension in medical practice. Milit Med 143, 249-255.

25. BaLINT, M (1963). The Doctor, His Patient and the Illness. Pitman. London.

26. Cook, E L (1964). Group therapy in a military community. Int $J$ Group Psychother 14, 374-377.

27. PARrish, M D (1972). A veteran of three wars looks at psychiatry in the military. Psychiatr Opinn 9, 6-11.

28. SteINER, J (1976). Some aspects of interviewing technique and their relationship with the transference. Br J Med Psychol 49, 65-72.

29. MoffetT, L A and Stoklosa, J M (1976). Group therapy for socially anxious and inassertive young veterans. Int J Group Psychother 26, 421-430. 